\title{
Biofouling in Water Systems
}

\author{
L. F. Melo \\ School of Chemical Engineering, \\ The University of Birmingham, \\ Birmingham B15 2TT, \\ United Kingdom \\ T. R. Bott \\ Centre of Biological Engineering, \\ University of Minho, \\ Campus de Gualtar, \\ 4700 Braga, \\ Portugal
}

- The paper describes the mechanisms in the development of biofouling layers (initial surface conditioning, microbial transport and attachment, mass transfer of nutrients to the biofilm surface and through the microbial layer, cell metabolism, and detachment of cells and of larger parts of the biofilm) and summarizes the effects of several factors on the buildup and stability of biofilms (nutrient availability, fluid velocity and turbulence, temperature, surface condition, and nonliving particles). Mass transfer within biofilms is treated in more detail. A biofouling model applied to the development of biofilms in heat exchangers is presented. Finally, references are made to biofouling control methods (biocide and the proper design and operation of heat exchangers) and to future research needs in this area. (C) Elsevier Science Inc., 1997

Keywords: biofouling, water, mass transfer, mathematical model, mitigation

\section{INTRODUCTION}

Biofouling of surfaces involves living matter-either micro- or macroorganisms. The former are small, often single cell entities (e.g., bacteria, fungi, or algae), and the latter are larger creatures (such as mussels and barnacles). In heat exchangers, the problem of biofouling especially involves bacteria, although the debris from fungal and algal activity also may be a problem. In some systems, such as seawater-cooled equipment, macroorganisms may create operational difficulties.

The condition is generally experienced where aqueous systems are present (e.g., in cooling water systems, paper mill operations, and in water treatment plants), but it may be present where there is a suitable environment for microorganisms to exist and thrive. The industrial problems associated with biofouling are essentially those that accrue to all fouling mechanisms - namely, increased back pressure for a given flow rate and, in heat exchangers, reduced heat transfer for a given temperature difference.

This paper discusses the incidence of bacteria on surfaces and the factors that affect deposition and growth and focuses mainly on cooling water systems, given that membrane fouling is discussed elsewhere.

\section{BIOFILM FORMATION}

For a surface to become contaminated by bacteria, the individual cells or clusters of cells have to move toward that surface. The process entails the theory of mass trans- fer applied to small particles. During their metabolism, bacteria generate waste products that, by virtue of mass transfer, move away from the surface.

It would appear that, in nature, bacteria prefer to reside on a surface in an aqueous environment rather than to be "free floating." There are a number of possible reasons for this: for instance, the surface could be a source of nutrients from adsorbed material. The continuous flow of water across the surface also provides a continuous supply of nutrients, and the aeration provides oxygen for aerobic species. Furthermore, the removal of waste materials from the biofilm is facilitated by mass transfer processes. Fletcher [1] suggested that the solid surface may afford protection for the bacteria and survival may be enhanced in biofilms. The individual microorganisms are likely to be smaller than the crevices and roughness of the surface, so they are able to "hide" from the removal effects of flow across the surface.

"Natural" water contains a large number of macromolecules that are the result of the breakdown of formerly living material. These substances quickly adsorb onto solid surfaces emersed in the water in preference to the microorganisms. It is this adsorbed layer to which the colonizing bacteria attach, perhaps attracted, as already mentioned, by virtue of its nutrient quality. For this reason, there is usually a "delay" time, or initiation period, before the biofilm begins to develop (Fig. 1). Quite apart from the possible "chemitaxis" to the surface, electrical forces also may take part in the adhesion process; that is, the charge on a microorganism may be different from that of the surface, giving rise to attraction (or possibly repulsion).

Address correspondence to Dr. T. R. Bott, School of Chemical Engineering, The University of Birmingham, Edgbaston, Birmingham B15 2TT, United Kingdom. 


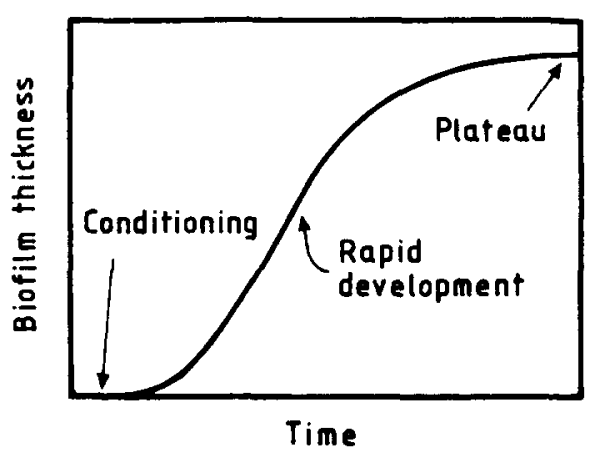

Figure 1. An idealized biofilm development curve.

It has been suggested [2] that the initial bonding of the bacteria to the surface is reversible, but, after a period of time, the adhesion becomes more substantial and irreversible. Bacteria finding themselves in crevices are more likely to form a permanent bond compared with those residing on an "exposed" part of the surface, because they have more opportunity to do so. It is possible that the more permanent condition arises from a chemical bridging between the cell and the adsorbed macromolecules.

The general development of a biofilm with time is shown in Fig. 1. After the conditioning and initiating of biofilm growth, there is a rapid development in biofilm thickness. After a further period, the thickness of the biofilm becomes stabilized about a mean value. At the plateau, it is considered that the factors that enhance growth (e.g., nutrient availability) are offset by the removal forces owing to the fluid shear.

In summary, the sequence of events in biofilm formation are:

1. Mass transfer of macromolecules to the surface and the formation of an adsorbed layer;

2. Transport of microorganisms to the adsorbed layer;

3. Irreversible adhesion of the cells or clusters to the surface;

4. Possible removal of cells from the surface;

5. Establishment of a stronger bond between the microorganisms and the surface layers;

6. Mass transfer of nutrients to the surface and through the biofilm together with transport away from the surface;

7. Cell metabolism, including the production of new cells and extracellular polymers; and

8. Possible sloughing of the biofilm when it has attained a critical thickness.

The morphology of a biofilm that may be observed on a surface is very dependent on the prevailing conditions (e.g., nutrient availability, water flow rate, temperature, and $\mathrm{pH})$. The biofilm can contain strands of cells or clusters that grow out from the surface toward the bulk liquid or it can be irregular with interstices. The compactness of the biofilm, therefore, is variable, and it will generally contain in excess of $90 \%$ water. The morphology and structure of a biofilm is likely to change as the biofilm ages and will be dependent on external conditions, particularly with respect to nutrient availability and velocity of flow over the biofilm.

It is unusual to observe "pure" biofouling in industrial equipment. Biofilms can encourage other fouling mecha- nisms - for instance, corrosion due to a change in local $\mathrm{pH}$ resulting from microbial activity. Crystallization may similarly be enhanced. The sticky character of biofilms can encourage the retention of particulate matter, as discussed later.

In mixed systems of microorganisms, there can be interactions between different species of cells that may be beneficial or detrimental to the organisms.

From this brief outline of microbial activity, it can be seen that biofilm formation is a complex phemomenon and is subject to the prevailing conditions. The remainder of this paper seeks to explore the effects of some of the system variables on the biofouling process within an industrial context.

\section{FACTORS AFFECTING BIOFOULING}

A number of factors affect the growth of biofilms on industrial equipment (i.e., those that are associated with cell metabolism and the engineering factors).

\section{Nutrient Availability}

In open recirculating systems, there is abundant opportunity for the water to "pick up" nutrients, particularly in cooling towers and spray ponds. Closed systems (i.e., not exposed to the atmosphere) are ideal systems in that the problem of biofouling is either uniikely to be encountered or at least reduced.

It has been demonstrated that the availability of nutrients has a marked effect on the biofilm thickness obtained [3]. For a given velocity of $1.2 \mathrm{~m} / \mathrm{s}$ through a tube, raising the nutrient level (based on glucose) from $4 \mathrm{mg} / \mathrm{L}$ to 10 $\mathrm{mg} / \mathrm{L}$ gave an increase of biofilm thickness of more than $400 \%$. High levels of nutrient appear to produce an "open" structure in the biofilm; lower concentrations tend to give a more compact structure. It is also interesting to note that, when a surface has been contaminated with bacteria and nutrients are available, the biofilm will continue to develop, even though there are no further microorganisms in the aqueous phase. This observation has implications for biofilm control, suggesting that it is the biofilm itself that requires attention and not the planktonic microorganisms.

The structure of the biofilm has an effect on the availability of nutrients to the constituent cells. An open structure facilitates the diffusion of nutrients to the bacteria remote from the aqueous phase. For aerobic bacteria, the availability of oxygen is necessary unless the particular microorganism can exist under oxygen-starved conditions. In general, open circulating systems will contain water saturated with oxygen owing to the aeration provided by intimate contact between water and air during the evaporative cooling process. It was shown for a biofilm grown under a velocity of $0.7 \mathrm{~m} / \mathrm{s}$ that the oxygen concentration at the biofilm solid surface interface was zero when the biofilm had a thickness of about $300 \mu \mathrm{m}$ [4]. At a higher flow velocity of $2.0 \mathrm{~m} / \mathrm{s}$, the condition of zero oxygen at the interface was reached when the biofilm thickness was of the order of $600 \mu \mathrm{m}$. The difference between these observations is attributed to the higher mass transfer 
effects at the water-biofilm interface at the higher velocity. These data emphasize the interaction between nutrient availability and flow velocity.

\section{Velocity and Turbulence}

A "rule of thumb" suggests that, to reduce the incidence of biofouling in tubular heat exchangers, the velocity should be in excess of $1 \mathrm{~m} / \mathrm{s}$. Research on the effects of velocity has confirmed the validity of this statement, at least for the tube diameters found in industry.

There is also some evidence [5] to suggest that Reynolds number also affects biofilm growth; but, because of the reasonably constant physical properties of water and the limited range of tube size used in shell and tube heat exchangers, it is fluid velocity that affects biofilm growth. For a given Reynolds number of 11,000 and fixed conditions of nutrient concentration, it was shown that, for a velocity of $0.54 \mathrm{~m} / \mathrm{s}$, the biofilm thickness after 15 days was ten times as thick as the biofilm developed under a 2 $\mathrm{m} / \mathrm{s}$ water flow. Velocity also affects the density of the biofilm [6, 7]. Experiments with Pseudomonas fluorescens showed that, as the velocity increased from $0.13 \mathrm{~m} / \mathrm{s}$ to $0 / 54 \mathrm{~m} / \mathrm{s}$, the density of the dry biofilm increased from $26 \mathrm{~kg} / \mathrm{m}^{3}$ to $76 \mathrm{~kg} / \mathrm{m}^{3}$ (dry mass/wet volume). There are implications with respect to the penetration of biocides for the differencies in biofilm density and corresponding velocity.

\section{Temperature Effects}

For many bacteria found in cooling water, the optimum temperature for maximum growth is about $40^{\circ} \mathrm{C}$, which is the level of temperature likely to be encountered in industrial water coolers, particularly in summer. At this temperature, small changes in temperature are likely to produce substantial changes in biofilm growth because microbial activity is very sensitive to temperature. For instance, it was shown that biofilm thickness increased by some $80 \%$ by raising the temperature from $30^{\circ}$ to $35^{\circ} \mathrm{C}$ [8]. The bacterium was $E$. coli.

\section{Surface Condition}

It has already been suggested that the surface condition (e.g., whether rough or smooth) affects the ability of bacteria to adhere to a surface. Work carried out by using tubes of different materials, demonstrated that smooth surfaces (e.g., glass and electropolished 316 stainless steel) had $35 \%$ less biofilm deposition than did a corresponding "as received" 316 stainless steel tube [9]. Fluorinated ethylene polypropylene gave a similar reduction in biofilm accumulation. The fluid velocity through the tubes was 1.0 $\mathrm{m} / \mathrm{s}$ in these experiments. The bacterium was Pseudomonas fluorescens.

\section{Effect of Particles}

Usually, biofouling of industrial equipment occurs together with other kinds of fouling [10], the most common of all being the simultaneous deposition of small particles that are transported with the incoming water or are formed in the plant as a consequence of metal corrosion. When the particles are of organic nature, they can act as sub- strates for the microorganisms and be degraded by them, contributing to the growth of the biomass. In most cases, however, the biological matrix incorporates inorganic particles (clay, sand, iron oxides) that are relatively inert from a strict metabolic standpoint but may nevertheless cause changes in the structure and activity of the biofilm.

A reasonable amount of data on the interaction between inorganic particles and microorganisms in soils and liquid suspensions has been published [11-15]. In general, it was found that (1) adhesion between particles and microorganisms could be facilitated by the electropositive charges developed at the surfaces of some particles (e.g., clay), depending on the $\mathrm{pH}$ of the environment; (2) metabolic inhibitors and toxic metallic ions could be absorbed on the particle surfaces, favoring biomass formation; and (3) microbial respiration was stimulated in the presence of particles. Powdered clay was used in a nitrifying activated sludge reactor, and the result was an increase in biomass activity [16, 17]. In some cases [18], very small particles (1-100 nm, much smaller than microorganisms) had a detrimental effect on the biological process, because they covered the surface of the cells and obstructed mass exchange with the environment.

Few results have been published on the role of inorganic particles within biofilms formed in flow conditions. Lowe et al. [19] reported an increase in the biofilm mass when the flowing water contained $50 \mathrm{mg} / \mathrm{L}$ of kaolin particles. The additional mass of the inorganic particles incorporated into the microbial layer was not the only explanation for this increase, because the organic content of the biofilm also was significantly higher. No effect was detected when a low kaolin concentration, about $5 \mathrm{mg} / \mathrm{L}$, was used [20]. At high concentrations $(5000 \mathrm{mg} / \mathrm{L})$, a scouring effect was noticed when sand particles were used, although this did not happen with clay particles. The erosive effect may indeed explain the very low level of biofouling measured in some power station condensers, using cooling water that contained particulate matter [21].

Oliveira et al. [22] and Melo and Vieira [23] also reported an increase in the amount of biofilm formed under turbulent flow conditions in the presence of $150 \mathrm{mg} / \mathrm{L}$ of suspended kaolin particles (equivalent diameter in the range of $10-20 \mu \mathrm{m}$ ). These authors also found that the mass transfer coefficient of lithium chloride through the biofilms was enhanced by the incorporation of clay particles in the biological matrix (Fig. 2), and that such biofilms resisted detachment for a longer time than did particle-free biofilms when nutrients were excluded from the flowing liquid [23].

Apart from the effect that the clay particles seem to have on the physical structure of the microbial film, the particles could also contribute to the maintenance of a suitable $\mathrm{pH}$ value within the biofilm on account of their well-known adsorptive and ion-exchange properties [22, 23]. Srinivasan et al. [24] reported that biofilms grown in the presence of abiotic particles (kaolin or calcium carbonate, $50 \mathrm{mg} / \mathrm{L}$ ) were more resistant to the action of a biocide than those developed in media free of particles. Thus, the results published so far indicate that incorporation of particles (especially clays) can result in a more open and mechanically stronger structure of the biological layer and may create a better environment for the activity of the cells by adsorbing inhibitors and maintaining the $\mathrm{pH}$ at suitable levels. 


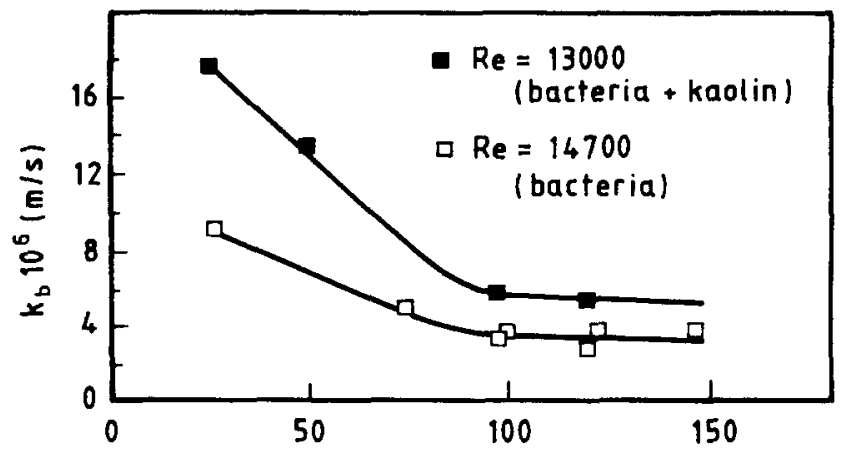

(h)

Figure 2. Mass transfer coefficients of lithium chloride within biofilms formed by Pseudomonas fluorescens with (solid squares) and without (open squares) clay particles as a function of time.

\section{MASS TRANSFER IN BIOFOULING}

The development of the biofouling layer is dependent on the rate at which nutrients and substrates reach the surface of the biofilm, as discussed earlier. Therefore, the higher the water velocity and the concentration of those components, the higher the growth rate of the microbial film tends to be.

However, substrate consumption may be limited by slow mass transfer within the biofilm, depending on the structure of the biological matrix. Higher fluid velocities usually lead to denser or more compact biofilms, as confirmed by several authors $[6,7,25]$. Furthermore, the mass diffusivities, at least for biofilms subject to conditions similar to those prevailing in heat exchangers (e.g., turbulent flow and low substrate concentration), will be low. These authors used an inert tracer (lithium chloride) in their experiments. When a biodegradable substance is used-whether it is a substrate or a biocide - the concentration profiles are determined by both diffusion and reaction inside the deposit, which can easily lead to only a partial penetration of that substance in the biofilm, with obvious negative consequences either for biofouling development (in the case of substrate diffusion) or for biofouling control (in the case of biocide diffusion).

Some authors have shown that mass transfer mechanisms inside biofilms could include not only molecular diffusion, but also convection [26,27], mainly in the cases where biofilms were formed under conditions typical of biological wastewater treatment (low fluid velocities and high substrate concentrations). In such cases, values of mass transfer coefficients through the biological deposit, such as those measured by Siegriest and Gujer [28] in agitated reactors or by Vieira et al. [7] in ducts, are particularly useful for quantifying mass transfer in biofilms, because those coefficients include all types of transport mechanisms. The existence of convective flows inside the biofouling layer has important consequences, because it means that transport in the biofilm can be directly affected by changes in the external flow conditions. For example, the penetration of biocides could be improved by increasing the liquid velocity simultaneously with the introduction of the biocide in the water stream.

\section{MODELING BIOFOULING IN HEAT EXCHANGERS}

Several models have been proposed to describe the formation and activity of biofilms, mainly for the purpose of modeling wastewater treatment processes [29-31]. The models can be written in terms of biomass production rate or in terms of substrate consumption rate [32]. As far as heat exchangers and cooling water systems are concerned, the first approach seems to be preferable; nevertheless, the incorporation of the concepts usually associated with wastewater treatment (the second approach), such as the theory of diffusion-reaction in catalysts, is also very useful for a better understanding of biofouling.

Biological deposits in heat exchangers are formed under specific conditions that are quite apart from those prevailing in most wastewater reactors: the concentration of substrate is very low (a few milligrams per liter in heat exchangers compared with thousands of milligrams per liter in wastewater reactors), and the velocity is very high ( $1 \mathrm{~m} / \mathrm{s}$ compared with $1 \mathrm{~m} / \mathrm{h}$ or even $1 \mathrm{~m} /$ day). This means that biofilms in cooling water heat exchangers tend to be much thinner than those formed in bioreactors used for pollution control. The concentration of substrate within the biofilms also is much lower in the first case. Therefore, if the diffusion-reaction concept is to be applied, a firstorder reaction should be considered, but diffusional limitations can be expected in some cases.

Biofouling rates, like rates of other types of fouling, are determined by the competition between a "deposition rate" and a "removal rate," the latter representing the detachment processes. In biofouling, the deposition term accounts for the development of the biofilm due to the adhesion and incorporation of new cells coming from the liquid, but principally to the growth and reproduction of microorganisms in the biofilm associated with substrate consumption.

According to Bryers and Characklis [33], the rate of cell adhesion $\left(r_{\mathrm{Xad}}\right.$, biomass adhered per unit time and unit surface area) follows a first-order process; that is,

$$
r_{\mathrm{Xad}}=k_{\mathrm{Xad}} C_{\mathrm{X}}
$$

where $k_{\mathrm{Xad}}$ is the rate constant for cell adsorption and $C_{\mathrm{X}}$ is the bulk concentration of cells in suspension (mass per unit volume).

The rate of biomass production due to consumption depends on the rates of three phenomena occurring in series: mass transfer of substrate to the biofilm-water interface, mass transfer inside the biofilm, and biochemical reaction inside the biofilm. If $K_{\mathrm{m}}$ is the external mass transfer coefficient and $k_{1}$ is the first-order reaction rate constant, it can be shown, according to the models of heterogeneous catalysis $[34,35]$ that

$$
r_{\mathrm{Xs}}=Y \frac{C_{\mathrm{s}}}{\frac{1}{K_{\mathrm{m}}}+\frac{1}{\eta k_{1} y_{\mathrm{f}}}},
$$

where:

- $r_{\mathrm{XS}}$ is biomass production due to the consumption of substrate (biomass produced per unit time and unit surface area)

- $Y$ is biomass yield (biomass produced per unit mass of consumed substrate) 
- $C_{\mathrm{s}}$ is bulk substrate concentration (mass per unit volume)

- $\eta$ is biofilm efficiency (quotient between the actual rate of substrate consumption by the biofilm and the ideal rate of consumption if there were no mass transfer limitations inside the biofilm), dimensionless

- $y_{\mathrm{f}}$ is biofilm thickness

The efficiency of the biofilm decreases as the biofilm thickness increases; furthermore, biomass production is the result not only of cell reproduction, but mostly of the excretion of extracellular substances by the microorganisms present in the biofilm. That is, when a biofilm grows, the fraction of cellular mass that it contains decreases with time, meaning that the relative potential for biomass production also increases. If these contradictory effects are taken into account, the rate of biomass production $r_{\mathrm{Xs}}$ may be considered to be approximately constant with time. The "deposition" rate $\Phi_{\mathrm{d}}=r_{\mathrm{Xs}}$.

The "removal rate," $\Phi_{\mathrm{r}}$ (mass of biofilm detached per unit time and per unit surface area) is usually considered to be proportional to the mass of biofilm per unit surface area, $m_{\mathrm{f}}$, and the respective proportionality constant depends on the mechanical resistance of the biofilm to the external forces that may cause its detachment (fluid forces):

$$
\Phi_{\mathrm{r}}=b m_{\mathrm{f}} .
$$

The general equation representing the biofouling rate is then

$$
\frac{d m_{\mathrm{f}}}{d t}=\Phi_{\mathrm{d}}-\Phi_{\mathrm{r}},
$$

which, upon integration, assuming $\Phi_{\mathrm{d}}$ constant, yields

$$
m_{\mathrm{f}}=m_{\mathrm{f}}^{*}[1-\exp (-b t)],
$$

where $m_{\mathrm{f}}^{*}$ is the "steady state" maximum amount of deposit and $b$ is a parameter that represents the inverse of the resistance of the deposit to removal:

$$
m_{\mathrm{f}}^{*}=\Phi_{\mathrm{d}} / b .
$$

Use of the preceding equations to predict biofouling rates is difficult, unless the values of a few parameters are known. For example, it is quite difficult, if not impossible, to predict values of the biofilm efficiency or of the reaction rate constant in Eq. 2. Therefore, the existing models are primarily useful for interpreting biofouling data and for a better understanding of the phenomena involved.

In industrial heat exchangers, the rate of biofouling can be monitored by means of heat transfer measurements, resulting in values of the thermal resistance of the deposit $\left(R_{\mathrm{f}}, \mathrm{m}^{2} \mathrm{~K} / \mathrm{W}\right)$. To apply the above model to such data, it is necessary to convert thermal resistance units into biofilm mass (per unit area) by using following expression:

$$
m_{\mathrm{f}}=R_{\mathrm{f}} \cdot \rho_{\mathrm{f}} \cdot K_{\mathrm{f}} \text {, }
$$

where $\rho_{\mathrm{f}}\left(\mathrm{kg} / \mathrm{m}^{3}\right)$ and $K_{\mathrm{f}}[\mathrm{W} /(\mathrm{m} \mathrm{K})]$ are the density and the thermal conductivity of the deposit, respectively. Because the biofilm mass is mainly water $(90-99 \%)$, the values for these properties can be considered equal to those of the water.

\section{BIOFILM CONTROL}

An important consideration in the operation of equipment subject to biofouling is its mitigation. Discussion in the section titled "Factors Affecting Biofouling" provided information on the effects of system variables on the development of biofilms, and these comments are of considerable relevance to the design and operation of equipment, particularly heat exchangers, to limit the effects of microbial growth. Despite attention to engineering factors such as velocity, temperature, or surface condition, it is still likely that biofouling will occur; and, to maintain efficiency, it is necessary to take further steps to reduce or eliminate the problem. Costs are minimized if these additional measures are taken into account at the design stage rather than as a retrofit application. Mitigation techniques may be broadly divided into two groups: mechanical and chemical methods. The various technologies have been described and discussed $(32,36)$.

\section{Mechanical Techniques}

Mechanical methods usually include the physical removal of biofilm from the surface. Such a technique may be applied "online" when the equipment is operating or "offline" when the equipment is shut down. Online methods may be used on a nearly continuous basis or intermittently, depending on the particular problem.

A method that has become increasingly popular in the past few years, for the maintenance of power station condenser heat transfer efficiency, is the circulation of sponge rubber balls with the cooling water. The method is very suitable in this application because power station condensers are large units consisting of many tubes of a standard diameter. The concept is that each tube receives a ball on a regular basis so that the biofilm associated with the water flow through the tubes is wiped away. In general, the technology is effective, but, from time to time, problems can arise if a ball is unable to pass through a tube, perhaps because of a partial blockage.

A modification of the sponge rubber ball idea is that a brush oscillates within the tubes through which the cooling water is flowing, by automatic flow reversal. The periodicity of the reversal depends on the severity of the biofouling problem. A difficulty may arise from the unacceptability of the flow reversal. On the other hand, the method has the advantage that it may be applied to individual heat exchangers on an industrial site where application of the sponge rubber ball system would not be economical.

Modification of the solid surface onto which the biofilm attaches has been used to reduce biofouling. In food processing, highly polished surfaces are generally employed to reduce fouling, including biofouling, and, in the food industry, this has implications with respect to hygiene. Coating the surface with a suitable polymer can render it less hospitable to biofilm attachment. The addition of a coating on the surface, however, since it has a finite thickness, constitutes a "fouling" resistance in its own right.

Novel techniques that are currently under investigation include the use of electric fields to "hold off" the cells from the surface and the use of ultrasound to create cavitation at the solid surface.

Restoration of heat transfer efficiency by offline mechanical cleaning usually involves the use of high-pressure 
water jets or manual cleaning for equipment such as plate heat exchangers.

\section{Chemical Methods}

An obvious way of coping with the problem of living organisms is to use a disinfectant, usually called a biocide. Applications of chemicals to kill microorganisms may be used on a continuous basis or intermittently, depending on the severity of the problem and cost. In general, relatively low concentrations of biocide are required. Frequency of dosing in relation to biocide concentration can optimize the cost of mitigating the problem. Chlorine was, for many years, the preferred biocide, generally requiring concentrations of about $1 \mathrm{mg} / \mathrm{L}$, but the products of chlorine reactions with organic matter are toxic and may be carcinogenic. Furthermore, chlorine persists in the environment and may enter the food chain. For these reasons, the use of chlorine is being curtailed in favor of more environmentally acceptable biocides (e.g., hydrogen peroxide and ozone). There are also a number of organic compounds that are used (e.g., gluteraldehyde), as well as propriety mixtures of complex organic compounds.

In addition to biocides, dispersants are employed to maintain the cells in suspension, thereby reducing the opportunity to stick to solid surfaces. Care has to be exercised in the use of chemical additives for combating biofilm formation so as to avoid corrosion of the equipment in contact with the cooling water.

Chemicals may also be used for offline cleaning (e.g., the use of detergents). Cell rupture may be achieved through the use of concentrated salt solutions to produce osmotic pressures, which facilitates biofilm removal. Metal corrosion may be an unwanted result of this technique.

\section{CONCLUSION}

Biofouling in cooling water is a complex process affected not only by the mechanical features of the equipment and the conditions of operation, but also by the metabolic requirements of the microorganisms. A great deal of research has already been published on the effects of different variables, but, as research equipment becomes more sophisticated, it becomes more and more possible to investigate mechanisms at the microbe level. Such knowledge may assist in a better understanding of potential mitigation techniques.

There is, however, a genuine need to improve understanding of how to overcome problems of biofouling and wherever possible to prevent the formation of biofilms. The public concern for the environment and the strengthening of legislation with respect to pollution makes it imperative that chemical additives in combination with mechanical methods of mitigation offer an acceptable solution. It will have to be recognized, however, that the cost will be very much greater than the cost associated with the use of chlorine.

\section{NOMENCLATURE}

$b$ detachment (removal) constant, $\mathrm{s}^{-1}$

$C_{\mathrm{s}}$ substrate bulk concentration, $\mathrm{kg} / \mathrm{m}^{3}$

$C_{\mathrm{X}}$ cell concentration in the bulk liquid, $\mathrm{kg} / \mathrm{m}^{3}$

$k_{1}$ first-order reaction constant in the biofilm, $\mathrm{s}^{-1}$
$K_{\mathrm{f}}$ thermal conductivity of the biofilm, W/(m K)

$K_{\mathrm{m}}$ mass transfer coefficient of substrate in the liquid, $\mathrm{ms}^{-1}$

$k_{\mathrm{X} \text { ad }}$ rate constant for cell adhesion, $\mathrm{s}^{-1}$

$m_{\mathrm{f}}$ mass of deposit (biofilm) at any instant $t$, per unit surface area, $\mathrm{kg} / \mathrm{m}^{2}$

$m_{\mathrm{f}}^{*}$ asymptotic mass of deposit, per unit surface area, $\mathrm{kg} / \mathrm{m}^{2}$

$R_{\mathrm{f}}$ thermal resistance of the biofilm, $\mathrm{m}^{2} \mathrm{~K} / \mathrm{W}$

$r_{\text {Xad }}$ rate of cell adhesion, $\mathrm{kg} /(\mathrm{ms})$

$r_{\mathrm{Xs}}$ rate of biomass production in the biofilm, $\mathrm{kg} /(\mathrm{ms})$

$t$ time, s

$y_{\mathrm{f}}$ thickness of wet biofilm, $\mathrm{m}$

$Y$ biomass produced per unit mass of consumed substrate, $\mathrm{kg} / \mathrm{kg}$

\section{Greek Symbols}

$\eta$ biofilm efficiency, dimensionless

$\Phi_{\mathrm{d}}$ deposition rate, $\mathrm{kg} /(\mathrm{ms})$

$\Phi_{\mathrm{r}}$ detachment or removal rate, $\mathrm{kg} /(\mathrm{ms})$

$\rho_{\mathrm{f}}$ density of wet biofilm, $\mathrm{kg} / \mathrm{m}^{3}$

\section{REFERENCES}

1. Fletcher, M., Bacterial Metabolism in Biofilms. In Biofilms: Science and Technology, L. F. Melo, T. R. Bott, M. Fletcher, and B. Caperville, Eds., pp. 113-124, Kluwer, Dordrecht, 1992.

2. Costerton, J. W., Geesey, G. G., and Cheng, K. J., How Bacteria Stick. Sci. Am. 238(1), 86-96, 1978.

3. Bott, T. R., and Miller, P. C., Mechanisms of Biofilm Formation on Aluminium Tubes. J. Chem. Tech. Biotechnol. 33B, 177-184, 1983.

4. Patel, T. D., and Bott, T. R., Oxygen Diffusion Through a Developing Biofilm of Pseudomonas fuorescens. J. Chem. Tech. Biotechnol. 52, 187-199, 1991.

5. Pujo, M., and Bott, T. R., Effects of Fluid Velocities and Reynolds Numbers on Biofilm Development in Water Systems. In Experimental Heat Transfer, Fluid Mechanics and Thermodynamics, J. F. Keffer, R. K. Shah, and E. N. Ganić, Eds., pp. 1358-1362, Elsevier, New York, 1991

6. Pinheiro, M. M., Melo, L. F., Bott, T. R., Pinheiro, J. D., and Leitao, L., Surface Phenomena and Hydrodynamic Effects on the Deposition of Pseudomonas fluorescens. Can. J. Chem. Eng. 66, 63-67, 1988.

7. Vieira, M. J., Melo, L. F., and Pinheiro, M. M., Biofilm Formation: Hydrodynamic Effects on Internal Diffusion and Structure. Biofouling 7(1), 67-80, 1993.

8. Bott, T. R., and Pinheiro, M. M. V. P. S., Biological Fouling: Velocity and Temperature Effects. Can. J. Chem. Eng. 55, 473-474, 1977.

9. Mott, I. E. C., Biofouling and Studies Using Simulated Cooling Water. PhD Thesis, Univ. Birmingham, Birmingham, UK, 1991.

10. Flemming, H. C., Biofouling in Water Treatment. In Biofouling and Biocorrosion in Industrial Water Systems, H. C. Flemming and G. G. Geesey, Eds., pp. 47-80, Springer Verlag, Berlin, 1991.

11. Stotsky, G., Influence of Clay Minerals on Microorganisms II: Effect of Various Clay Species, Homionic Clays and Other Particles on Bacteria. Can. J. Microbiol. 12, 831-848, 1966.

12. Filip, Z., and Hattori, T., Utilization of Substrates and Transformation of Solid Substrata. In Microbial Adhesion and Aggregation, K. C. Marshall, Ed., pp. 251-282, Springer Verlag, Berlin, 1984.

13. Burns, R. G., Interaction of Microorganisms, Their Substrates and Their Products with Soil Surfaces. In Adhesion of Microorganisms to Surfaces, D. C. Elwood, J. Melling, and P. R. Rutter, Eds., pp. 109-138, Academic Press, London, 1979. 
14. Burns, R. G., Microbial and Enzymic Activities in Soil Biofilms. In Structure and Function of Biofilms, W. G. Characklis and P. A. Wilderer, Eds., pp. 333-349, Wiley, New York, 1989.

15. Marshall, K. C., Adsorption of Microorganisms to Solids and Sediments. In Adsorption of Microorganisms to Surfaces, G. Bitton and K. C. Marshall, Eds., pp. 317-329, Wiley, New York, 1989.

16. Bowen, R. B., and Dempsey, B. A., Improved Performance of Activated Sludge with Addition of Inorganic Solids. Water Sci. Technol. 26(9-11), 2511-2514, 1992.

17. Chudoba, P., and Pannier, M., Use of Powdered Clay to Upgrade Activated Sludge Process. Environ. Technol. 15, 863-870, 1994.

18. Magdaliniuk, M. J., Block, J. C., Leyval, C., Bottero, J. Y., and Villemin, G., Biodegradation of Naphtalene in Montmorillonite/Polyacryamide Suspensions. Water Sci. Technol. 31(1), 85-94, 1995.

19. Lowe, M. J., Duddridge, J. E., Pritchard, A. M., and Bott, T. R., Biological Particulate Fouling Interactions: Effects of Suspended Particles on Biofilm Development. Proc. First UK National Heat Transfer Conf., Leeds, pp. 391-400, 1984.

20. Bott, T. R., and Melo, L. F., Particle-Bacteria Interactions in Biofilms. In Biofilms: Science and Technology, L. F. Melo, T. R. Bott, M. Fletcher, and B. Capdeville, Eds., pp. 199-206, Kluwer, Dordrecht, 1992.

21. Bour, D. P., Battaglia, P. J., and Burd, K. M., Biofouling Control Practice and Assessment. EPRI Report CS-1796, Palo Alto, 1981.

22. Oliveira, R., Melo, L. F., Pinheiro, M. M., and Vieira, M. J., Surface Interactions and Deposit Growth in Fouling of Heat Exchangers. Corrosion Rev. 11(1-2), 59-95, 1993.

23. Melo, L. F., and Vieira, M. J., Effect of Clay Particles on the Behaviour of Biofilms Formed by Pseudomonas fuorescens. Water Sci. Technol. 32(8), 45-52, 1995.

24. Srinivasan, R., Stewart, P., Griebe, T., Chen, C.-I., and Xu, X., Biocide Parameters Influencing Biocide Efficacy. Biotech. Bioeng. 46(6), 553-560, 1995.

25. Christensen, B. E., and Characklis, W. G., Physical and Chemical Properties of Biofilms. In Biofilms, W. G. Characklis and K. C. Marshall, Eds., pp. 93-130, Wiley, New York, 1990.
26. van den Heuvel, J. C., Mass Transfer in and Around Biofilms. In Biofilms: Science and Technology, L. F. Melo, T. R. Bott, M. Fletcher, and B. Capdeville, Eds., pp. 239-250, Kluwer, Dordrecht, 1992.

27. De Beer, D., and Stoodely, P., Relation Between the Structure of an Aerobic Biofilm and Transport and Phenomena. Water Sci. Technol. 32(8), 11-18, 1995.

28. Siegriest, H., and Gujer, W., Mass Transfer Mechanisms in a Heterotrophic Biofilm. Water Res. 19(11), 1369-1378, 1985.

29. Atkinson, B., and Daoud, I. S., The Analogy Between Micro-Biological "Reaction" Heterogeneous Catalysts. Trans. Inst. Chem. Eng. 46, T19-T24, 1968.

30. Characklis, W. G., Microbial Fouling: A Process Analysis. In Fouling of Heat Transfer Equipment, E. F. C. Somerscales and J. G. Knudsen, Eds., pp. 251-291, Hemisphere, Washington DC, 1981.

31. Capdeville, B., Nguyen, K. M., and Rols, J. L., Biofilm Modelling: Structural, Reactional and Diffusional Aspects. In Biofilms: Science and Technology, L. F. Melo, T. R. Bott, M. Fletcher, and B. Capdeville, Eds., pp. 251-276, Kluwer, Dordrecht, 1992.

32. Bott, T. R., Fouling of Heat Exchangers. Chap. 12, Elsevier Science B. V., Amsterdam, 1995.

33. Bryers, J. D., and Characklis, W. G., Biofilm Accumulation and Activity: A Process Analysis Approach. In Biofilms: Science and Technology, L. F. Melo, T. R. Bott, M. Fletcher, and B. Capdeville, Eds., pp. 221-237, Kluwer, Dordrecht, 1992.

34. Harremoes, P., Biofilm Kinetics. In Water Pollution Microbiology, R. Mitchell, Ed., Vol. 2, pp. 82-109, Wiley, New York, 1978.

35. Vieira, M. J., Estudo da formacao de filmes biologicos por Pseudomonas fluorescens e dos efeitos associados a transferencia de massa interna e a incorporacao de particulas de caulino. PhD Thesis, Univ. Minho, Braga, Portugal, 1995 (in Portuguese).

36. Bott, T. R., Fouling of Heat Exchangers and Its Mitigation with Special Reference to Biofouling. Proc. 2nd Eur. Thermal Sci. 14th UIT Nat. Heat Transfer Conf. 1, 115-125, 1996.

Received April 17, 1996; revised September 15, 1996 